\title{
Erratum to: Real Intelligent Design
}

\section{Erratum to:}

D. Harmon, A Naturalistic Afterlife https://doi.org/10.1007/978-3-319-57978-8_8

The chapter was inadvertently published with incorrect statement. The update in the incorrect statement has been incorporated as follows:

In Chap. 8, P. 151, second paragraph, second sentence, "Imagine that the moral design space ... aspirations: here, human flourishing (the $\mathrm{x}$ axis) and the flourishing of all other species (the $\mathrm{y}$ axis)." has been changed to read as "Imagine that the moral design space ... aspirations: here, human flourishing (the y axis) and the flourishing of all other species (the $\mathrm{x}$ axis)."

The updated original online version of this chapter can be found at https://doi.org/10.1007/978-3-319-57978-8_8 